American Journal of Biochemistry and Biotechnology 8 (1): 21-24, 2012

ISSN 1553-3468

(C) 2012 P.S. Choi et al., This open access article is distributed under a Creative Commons Attribution

(CC-BY) 3.0 license

\title{
Development of Transgenic Maize using Immature Embryos of HiII Genotype as a Vaccine Candidate
}

\author{
${ }^{2}$ Hyun A. Kim, ${ }^{2}$ Suk Yoon Kwon, \\ ${ }^{3}$ Han Sang Yoo, ${ }^{4}$ Moon Sik Yang and ${ }^{1}$ Pil Son Choi \\ ${ }^{1}$ Department of Medicinal Plant Resources, \\ Nambu University, Gwangju 506824, Korea \\ ${ }^{2}$ Department of System Biotechnology, \\ University of Science and Technology, \\ Green Bio Research Center, KRIBB, Daejeon, 305-806, Korea \\ ${ }^{3}$ Department of Infectious Diseases, \\ College of Veterinary, Seoul National University, Korea \\ ${ }^{4}$ Division of Biological Science, Chonbuk National University, Jeonju Korea
}

\begin{abstract}
Problem statement: Plant-based vaccines posses some advantages over other types of vaccine biotechnology such as safety, low cost of mass vaccination programs and wider use of vaccines for veterinary medicine. These study was undertaken to develop the transgenic maize as edible vaccine candidate for animals. Approach: The immature embryos of Hill genotype were inoculated with $A$. tumefaciens strain $\mathrm{C} 58 \mathrm{C} 1$ containing the binary vector V622. The vector was harbored nptII gene, which confers resistance to paromomycin and ApxIIA gene was produced ApxII toxin, which was generated in various serum types of A. pleuropneumoniae as a target gene. Results: The 1,027 immature embryos were immersed for $5 \mathrm{~min}$ in the Agrobacterium solution and then these were co-cultured on solid cocultivation medium at $28^{\circ} \mathrm{C}$ for 2 days. After the delay period, the scutellum explants, axis removed embryos, were cultured on medium with $50 \mathrm{mg} \mathrm{L}^{-1}$ paromomycin for first 2 weeks and a paromomycinresistant callus were sorted out on the selection medium with $100 \mathrm{mg} \mathrm{L}^{-1}$ paromomycin for $4 \times 14$ days. A total of twenty callus clones were selected and sixteen-putative transgenic plants were regenerated. Among them, only five plants contained the integrated $n p t I I$ gene, which was confirmed by Southern blot analysis. Conclusion: These results demonstrated that the nptII and ApxIIA genes integrated into the maize genome and that transgenic maizes can be use as vaccine candidate.
\end{abstract}

Key words: A. pleuropneumoniae, ApxIIA gene, nptII gene, paromomycin, immature embryo, transgenic maize

\section{INTRODUCTION}

Transgenic plants have been used in the production and delivery of edible oral subunit vaccines (Floss et al., 2007), because of some advantages, such as increased safety, anticipated low cost of mass vaccination programs and wider use of vaccinations for veterinary (Shin et al., 2011). Several plant-derived vaccine candidates have been developed and evaluated for their immunogenicity and protection against microbial infection (Daniell et al., 2001). Corn, one of the major forage crops available all over the world, is particularly attractive for its intensively studied genetics and the availability of established transformation procedures. In addition, grain seeds are appropriate systems for the oral delivery of subunit vaccines because of their low water contents and long periods of storage (Lamphear et al., 2004). Since many studies of the development of integration techniques into plants genome of antigen gene had been tried, the expression of its hetero-protein and of Hepatitis B surface Antigen (HBsAg) have been reported in tobacco plants (Curtiss and Cardineau, 1990) and in lettuce (Mason et al., 1992) respectively. After that, Mason et al. (1996) have been also reported the expression of Norwalk virus capsid protein in tobacco plants and potato tubers. Specially, potato tubers transformed with synthetic LT$\mathrm{B}$ gene have been reported higher LT-B concentration than bacteria-derived LT-B gene (Mason et al., 1998) and recently reported the possibility as a vaccine candidate of transgenic maize expressing ApxIIA gene using embryogenic calli co-cultivation transformation 
method (Kim et al., 2009). Like these, the expression of antigen-protein in plants could determine the suitability of the plants as a host and the availability of plant derived-antigen protein by injecting more visible. In this study, we developed the transgenic maize plants transformed with ApxIIA gene, the antigen gene of Actinobacillus pleuropneumoniae causing great loss in domestic hog-raising industry, using maize immature embryo transformation system.

The maize ear from plants of Hill genotype was harvested at 10-13 days after pollination and then was sterilized twice by spraying of $70 \%$ ethanol. After surface sterilization, a long forceps was plunged into the ear central-axis vertically to be easy to grab. The upper side of kernels were cut off using surgical blade (No.11) and then were carefully isolated the 1.5-2.0 $\mathrm{mm}$ size of immature embryos from each kernels by spatula. To avoid a drying of the immature embryos, the embryos were immersed in liquid co-cultivation medium on ice. The liquid co-cultivation medium $(\mathrm{pH}$ 5.4) contained MS salts, MS vitamins, MES, L-proline, sucrose, glucose, acetosyringone and $\mathrm{AgNO}_{3}$. Agrobacterium tumefaciens strain $\mathrm{C} 58 \mathrm{C} 1$ containing standard binary vector V622 was prepared by freezethaw method. The T-DNA (V622) contained two cassettes (Fig. 1); one is double $35 \mathrm{~S}$ promoterCTBapxII5-2(0.93 kb, ApxIIA) ORF-nos as target gene and other is double $35 \mathrm{~S}$ promoter-nptII ORF-nos as selectable marker. A. pleuropneumoniae ApxIIA gene produces ApxII toxin, which is synthesized in various serotype of $A$. pleuropneumoniae. A single colony of $A$. tumefaciens was grown in YEP liquid medium, which contains $50 \mathrm{mg} \mathrm{L}^{-1}$ rifampicin, $50 \mathrm{mg} \mathrm{L}^{-1}$ gentamycin and $50 \mathrm{mg} \mathrm{L}^{-1}$ kanamycin, at $28^{\circ} \mathrm{C}$ for 2 days and then the Agrobacteria solution was centrifuged at $3000 \mathrm{rpm}$ for $10 \mathrm{~min}$. The harvested pellet was suspended in the AB low-phosphate medium contained $5 \mathrm{~g} \mathrm{~L}^{-1}$ glucose, $4 \mathrm{~mL} \mathrm{~L}^{-1} \mathrm{AB}$ buffer, $50 \mathrm{~mL} \mathrm{~L}^{-1} \mathrm{AB}$ salts, $3 \mathrm{mM} \mathrm{MES}$, $200 \mu \mathrm{M}$ acetosyringone ( $\mathrm{AB}$ medium) and then incubated more till to $\mathrm{OD}_{650}=0.2$ for 16 hours. Cells were harvested and suspended to an $\mathrm{OD}_{650}$ between 0.60.8 with liquid co-cultivation medium (pH5.4) contained half-strength MS salts, $1 \mathrm{mg} \mathrm{L}^{-1}$ 2,4-D, 25 $\mathrm{mM}$ L-proline, $200 \mu \mathrm{M}$ acetosyringone, $1 \%$ glucose, $2 \%$ sucrose, Eriksson's vitamin, $100 \mathrm{mg} \mathrm{L}^{-1}$ casamino acids, $20 \mathrm{mM}$ MES for inoculation. Aseptically isolated immature embryos were immersed in A. tumefaciens suspension for $5 \mathrm{~min}$ and then was removed the Agrobacteria suspension by pipetting. The immature embryos were cultured on solid co-cultivation medium ( $\mathrm{pH} 5.4$ ) with half-strength MS salts, MS vitamins, 1 $\mathrm{mg} \mathrm{L}^{-1}$ 2,4-D, $20 \mathrm{mM}$ MES, $0.115 \mathrm{~g} \mathrm{~L}^{-1}$ L-proline, $2 \%$ sucrose, $1 \%$ glucose, $200 \mu \mathrm{M}$ acetosyringone, $5.5 \mathrm{~g} \mathrm{~L}^{-1}$ agarose (Sigma Ltd.), $20 \mu \mathrm{M} \mathrm{AgNO}_{3}$, dark condition, at $28^{\circ} \mathrm{C}$ for 2 days. The immature embryo to remove bacteria were cultured on delay medium with antibiotics (MS salts, Eriksson's vitamins, $0.5 \mathrm{mg} \mathrm{L}^{-1}$ thiamine-HCl, $1 \mathrm{mg} \mathrm{L}^{-1}$ 2,4-D, $3 \mathrm{mM}$ MES, $25 \mathrm{mM} \mathrm{L}-$ proline, $2 \%$ sucrose, $100 \mathrm{mg} \mathrm{L}^{-1}$ myo-inositol, $100 \mathrm{mg}$ $\mathrm{L}^{-1}$ casamino acid vitamin assay, $300 \mathrm{mg} \mathrm{L}^{-1}$ cefotaxime sodium, $0.7 \% \mathrm{BBL}$ agar and $1.7 \mathrm{mg} \mathrm{L}^{-1}$ $\mathrm{AgNO}_{3}, \mathrm{pH}$ 5.8) for 4-5 days. After 4-5 days, scutellum explants were carefully dissected from the germinated immature embryos and then were cultured on selection medium (pH5.8) with MS salts, MS vitamins, $0.4 \mathrm{mg}$ $\mathrm{L}^{-1}$ thiamine-HCL, $1 \mathrm{mg} \mathrm{L}^{-1}$ 2,4-D, $20 \mathrm{mM}$ MES, 0.115 $\mathrm{g} \mathrm{L}^{-1} \mathrm{~L}$-proline, $2 \%$ sucrose, $100 \mathrm{mg} \mathrm{L}^{-1}$ myo-inositol, $0.8 \%$ BBL agar (Gifco Ltd.), $300 \mathrm{mg} \mathrm{L}^{-1}$ cefotaxime sodium, $50 \mathrm{mg} \mathrm{L}^{-1}$ paromomycin at dark, $25^{\circ} \mathrm{C}$ for first two-weeks. After two weeks, the scutellum explants were sub-cultured at every two weeks on selection medium amended with $100 \mathrm{mg} \mathrm{L}^{-1}$ paromomycin for 8 weeks. Through 10 weeks of selection, embryogenic calli were induced from the scutellum explants. Of them, the embryogenic calli were rapidly showed proliferation and displayed a somatic embryo with white color. The embryogenic callus clones that proliferated on selection medium were cultured on the first regeneration medium for one week $\left(25^{\circ} \mathrm{C}\right.$, light $)$. Somatic embryos with greening were transferred onto second regeneration medium $\left(25^{\circ} \mathrm{C}\right.$, light). After $15-20$ days, regenerated plantlets in normal morphology were acclimated to soil and grown to maturity in greenhouse. The first regeneration medium $(\mathrm{pH} 5.8)$ contained MS salts, MS vitamins, $0.1 \mathrm{mg} \mathrm{L}^{-1}$ 2,4-D, 3mM MES, $2 \%$ sucrose, $100 \mathrm{mg} \mathrm{L}^{-1}$ myo-inositol, $0.1 \mathrm{mg} \mathrm{L}^{-1} \mathrm{ABA}, 150$ $\mathrm{mg} \mathrm{L^{-1 }}$ asparagine, $0.8 \% \mathrm{BBL}$ agar, $100 \mathrm{mg} \mathrm{L}^{-1}$ cefotaxime sodium, $50 \mathrm{mg} \mathrm{L}^{-1}$ paromomycin. The second regeneration medium ( $\mathrm{pH} 5.8)$ contained MS salts, MS vitamins, $3 \mathrm{mM}$ MES, $2 \%$ maltose, $100 \mathrm{mg} \mathrm{L}^{-1}$ myoinositol, $1 \%$ glucose, $150 \mathrm{mg} \mathrm{L}^{-1}$ asparagine, $0.5 \%$ agargel (Sigma Ltd.), $50 \mathrm{mg} \mathrm{L}^{-1}$ cefotaxime sodium. Plantlets $\left(\mathrm{T}_{0}\right)$ were acclimatized and grown to maturity in the greenhouse. The $T_{0}$ plants were artificially selfpollinated and the $T_{1}$ seeds were harvested. For Southern blot analysis, approximately $2 \mathrm{~g}$ of young leaves of putative transformants were prepared. The genomic DNA was isolated (Malmberg et al., 1985) and about 50 ug was digested with $\mathrm{BamHI} 16 \mathrm{~h}$ at $37^{\circ} \mathrm{C}$ and then electrophoresis on $0.8 \%$ agarose gel. The DNA in the agarose gel was blotted onto Zeta ${ }^{\mathrm{R}}$-Probe nylon membrane (Bio-Rad, catalog \#162-0196) in 20X SSC.

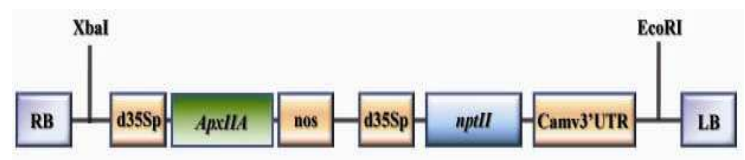

Fig. 1: T-DNA region of the binary pMYV vector (V622) harboring ApxIIA and nptII genes. The ApxIIA and nptII genes were driven by double cauliflower mosaic virus $35 \mathrm{~S}$ promoters, respectively 


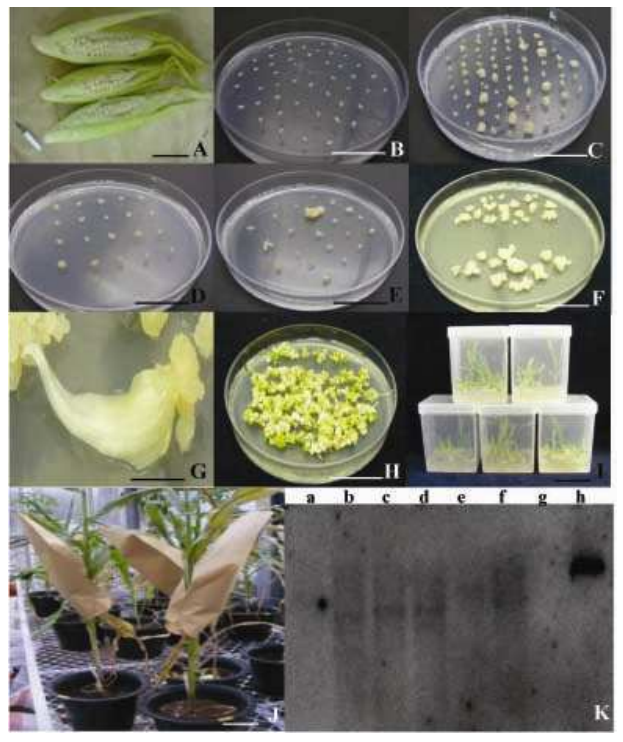

Fig. 2: Selection of paromomycin-resistant calli and plant regeneration from the selected callus clones after Agrobacterium strain (C58C1) carrying pMYV vector (622) co-cultivated. (A) The ear of Hi II genotype at 10-13 days of pollination (bar $=5$ $\mathrm{cm})$. (B) Immature embryos inoculated in $A$. tumefaciens solution (bar $=5 \mathrm{~cm}$ ). (C) Immature embryos on delay medium for 4-5 days (bar $=5$ $\mathrm{cm})$. (D) Scutellum explants on selection medium containing $50 \mathrm{mg} \mathrm{L}^{-1}$ paromomycin (bar $=5 \mathrm{~cm}$ ). (E) Outgrowth of paromomycin-resistant callus induced from scutellum explants on selection medium containing $100 \mathrm{mg} \mathrm{L}^{-1}$ paromomycin (bar $=5 \mathrm{~cm})$. $(\mathrm{F})$ Proliferation of paromomycin-resistant callus $($ bar $=5 \mathrm{~cm}) .(\mathrm{G})(\mathrm{bar}=2 \mathrm{~mm}),(\mathrm{H})(\mathrm{bar}=5$ $\mathrm{cm}$ ): Somatic embryos induced from callus clones. (I) Plantlets regenerated from somatic embryos in 2nd regeneration medium (bar $=6 \mathrm{~cm})$. (J) Pollination of transgenic plants in greenhouse (bar $=20 \mathrm{~cm})$. $(\mathrm{K})$ Southern blot analysis of putative transgenic plantlets $\left(\mathrm{T}_{0}\right)$; a: non-transgenic plant, b: Plant regenerated from experiment $\mathrm{B}, \mathrm{c}, \mathrm{d}$ : Plants regenerated from same callus clone of experiment A, e: Plant regenerated from experiment $\mathrm{C}$, f: Plant regenerated from experiment $\mathrm{F}$, g: Plant regenerated from experiment D, h: pMYV vector (622)

The 750-bp nptII PCR product was used and then labeled with ${ }^{32} \mathrm{P}$-dCTP (Amersham, catalog \#RPN1633). A pair of primers for PCR was 5'-GAG GCT ATT CGG CTA TGA CT-3' for Forward primer and 5'-ATC GGG AGC GGC GAT ACC GT3' for reward primer.

Agrobacterium transformation using immature embryos co-cultivation system in this study introduced two genes into the genome of maize, i.e., ApxIIA and the $n p t I I$ genes. The frequency (\%) and analysis of gene integration of this study were focused on the nptII gene; the frequency $(\%)$ based on the number of callus clones grew on selection medium containing paromomycin and the analysis of gene was verified using Southern blot analysis. The ear of HiII genotype was harvested after 10-13 days of pollination (Fig. 2A). The size of immature embryos $(1.5-2.0 \mathrm{~mm})$ were aseptically isolated and inoculated with suspension of $A$. tumefaciens strain $\mathrm{C} 58 \mathrm{Cl}$ carrying V622 binary vector for $5 \mathrm{~min}$ and then co-cultivated on solid co-cultivation medium at $25^{\circ} \mathrm{C}$, in dark for 2 days (Fig. 2B). During the delay period, some immature embryos were normally germinated without Agrobacteria colony or were expanded scutellum (Fig. 2C), but other died without growth or by contamination of Agrobacteria. When the scutellum explants after embryo axis removed were cultured on selection medium contained $50 \mathrm{mg} \mathrm{L}^{-1}$ paromomycin for first 2 weeks, a scutellum explants were more expanded (Fig. 2D) and a callus was initially identified from the edge of a few cotyledon at 21-30 days (Fig. 2E). The callus could rapidly proliferated during selection (Fig. $2 \mathrm{~F}$ ), but most of them did not grow (Fig. 2D and E). Based on observation on A-H experiments of 8 weeks, the average proportion of callus clones resistant to paromomycin was 20 independent clones out of 1,027 immature embryos inoculated (Table 1). Also, the average transformation efficiency-the number of paromomycin-resistant callus clones-was $2.1 \%$. The callus clones resistant to paromomycin were recovered 1-5 events from $\mathrm{A}-\mathrm{H}$ experiments and the range of transformation efficiency was $0.8-4.7 \%$. Experiment B indicated the highest efficiency $(4.7 \%)$ and the highest number of 6 putative transgenic plantlets produced from experiment A (Table 1). A total of sixteen plantlets $\left(\mathrm{T}_{0}\right)$ regenerated from each clones were acclimated and matured in greenhouse for molecular analysis (Table 1 and Fig. 2G-J). An efficient protocol of transformation in maize have been reported for immature embryo or embryogenic calli co-cultivation system using Agrobacterium (Ishida et al., 1996; Frame et al., 2002; Cho et al., 2005; Kim et al., 2009). According to many studies, the immature embryos of HiII genotype, that was produced type II callus, had been used for maize transformation (Frame et al., 2002). But, the efficiency of transformation varied among protocol and transformation materials. Based on the number of independent resistant calli on selection medium, Frame et al. (2002) and Utomo (2005) reported transformation efficiency of maize was 5.5 and 2.6\%. Especially, Kim et al. (2009) reported the transformation efficiency $(0.6 \%)$ of maize was decreased when embryogenic calli of HiII genotype used as explant. In this study, based on the number of independent paromomycin-resistant calli recovered, the transformation efficiency of immature embryos was higher $2.1 \%$ than embryogenic calli (Kim et al., 2009). Sixteen $\mathrm{T}_{0}$ putative transgenic plants have been produced as a result of 8 experiments. Genomic DNA of putative transgenic plantlets $\left(\mathrm{T}_{0}\right)$ was extracted from each leaf tissues and subjected to Southern blot analysis. 


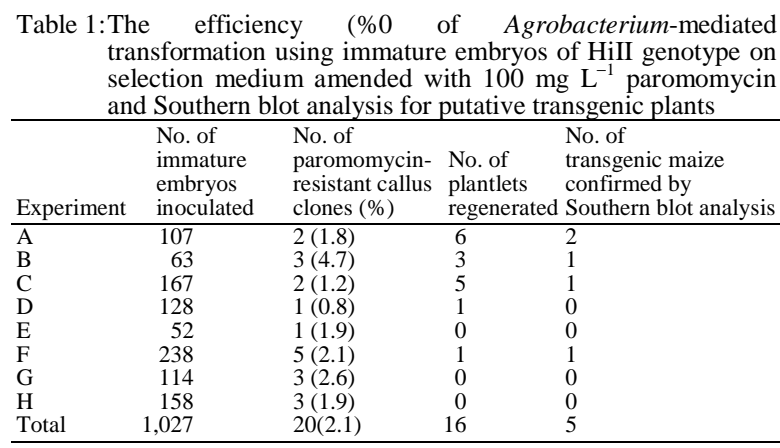

Sixteen plantlets were tested and the result showed that only 5 plantlets obtained from each experiments ( 2 for A, 1 for B, 1 for C, 1 for F) were stably introduced into maize genome and possessed the nptII gene as single, while other 11 plantlets were not detected (Fig. 2K). Among those five plants, only two $\mathrm{T}_{0}$ plants were outcrossed to produce seeds and $\mathrm{T}_{1}$ seeds were harvested; the other three $\mathrm{T}_{0}$ plants were failed to self- or outpollination. Southern blot analysis was used in this study to confirm the integration of transgenes into plant genome. As result, the integration of nptII gene in transgenic $\mathrm{T}_{0}$ maize was confirmed in five out of sixteen $\mathrm{T}_{0}$ plants tested. In conclusion, it is possible to develop a transgenic maize with ApxIIA as target gene and nptII as selectable marker. The events will be analyzed for the expression of ApxIIA gene, for the suitability of the maize as a host and for the availability of plant derived-antigen protein.

\section{CONCLUSION}

Transgenic maizes with nptII and ApxIIA gene were developed from the Agrobacterium-mediated transformation using immature embryos of maize, HilI genotype. The average transformation efficiency-the number of paromomycin-resistant callus clones-was $2.1 \%$ and the range of transformation frequency $(\%)$ according to experiment was $0.8-4.7 \%$. Finally, it could be confirmed that the nptII gene integrated into five maize genome by Southern blot analysis. The results shows that the use of immature embryos in Agrobacterium-mediataed transformation of maize was useful. This understanding may use for production of elite tansgenic event in maize and the transgenic plants may use as candidate vaccine for veterinary in further study.

\section{ACKNOWLEDGEMENT}

This study was supported by a grant (PJ008103) from the Biogreen 21 program, the Rural Development Administration (RDA).

\section{REFERENCES}

Cho, M.A., Y.O. Park, J.S. Kim, K.J. Park and H.K. Min et al., 2005. Yellowish Friable Embryogenic Callus (YFEC) Production and Plant Regeneration from Immature Embryo Cultures of Domestic Maize Cultivars and Genotypes (Zea may L.). Kor. J. Plant Biotech., 32: 1-5. DOI: 10.5010/JPB.2005.32.2.117
Curtiss, R.I. and C.A. Cardineau, 1990. Oral Immunisation by Transgenic Plants. World Patent Application, WO 90/02484.

Daniell, H., S.J. Streatfield and K. Wycoff, 2001. Medical molecular farming: Production of antibodies, biopharmaceuticals and edible vaccines in plants. Trends Plant Sci., 6: 219-226. DOI: 10.1016/S1360-1385(01)01922-7

Floss, D.M., D. Falkenburg and U. Conradm, 2007. Production of vaccines and therapeutic antibodies for veterinary applications in transgenic plants: An overview. Trans. Res., 16: 315-332. DOI: 10.1007/s11248-007-9095-x

Frame, B.R., H. Shou, R.K. Chikwamba, Z. Zhang and C. Xiang et al., 2002. Agrobacterium tumefaciensmediated transformation of maize embryos using a standard binary vector system. Plant Physiol., 129: 13-22.

Ishida, Y., H. Saito, S. Ohta, Y. Hiei and T. Komari et al., 1996. High efficiency transformation of maize (Zea mays L.) mediated by Agrobacterium tumefaciens. Nat. Biotechnol., 14: 745-750. DOI: 10.1038/nbt0696-745

Kim, H.A., S.D. Utomo, S.Y. Kwon, S.R. Min and J.S. Kim et al., 2009. The development of herbicideresistant maize: stable Agrobacterium-mediated transformation of maize using explants of type II embryogenic calli. Plant Biotech. Rep., 3: 277-283. DOI: 10.1007/s11816-009-0099-2

Lamphear, B.J., J.M. Jilka, L. Kesl, M. Welter and J.A. Howard et al., 2004. A corn-based delivery system for animal vaccines: An oral transmissible gastroenteritis virus vaccine boosts lactogenic immunity in swine. Vaccine, 22: 2420-4. DOI: 10.1016/j.vaccine.2003.11.066

Malmberg, R., J.W. Messing and I.M. Sussex, 1985. Molecular Biology of Plants: A Laboratory Course Manual. 1st Edn., CSHL Press, New York, ISBN: 9780879691844, pp: 150.

Mason, H.S., J.M. Ball, J.J. Shi, X. Jiang, M.K. Estes and C.J. Arntzen, 1996. Expression of Norwalk virus capsid protein in transgenic tobacco and potato and its oral immunogenicity in mice. Proc. Natl. Acad. Sci. USA., 93: 5335-5340.

Mason, H.S., L. Dominic Mam-Kit and C.J. Arntzen, 1992. Expression of hepatitis B surface antigen in transgenic plants. Proc. Nat. Acad. Sci. USA., 89: $11445-11749$.

Mason, H.S., T.A. Haq, J.D. Clements and C.J. Arntzen, 1998. Edible vaccine protects mice against Escherichia coli heat-labile enterotoxin (LT): potatoes expressing a synthetic LT-B gene. Vaccine, 16: 13361343. DOI: $10.1016 / \mathrm{S} 0264-410 \mathrm{X}(98) 80020-0$

Shin, M.K., M.H. Jung, W.J. Lee, P.S. Choi, Y.S. Jang and H.S. Yoo, 2011. Generation of transgenic cornderived Actinobacillus pleuropneumoniae ApxIIA fused with the cholera toxin B subunit as a vaccine candidate. J. Vet. Sci, 12: 401-403. DOI: 10.4142/jvs.2011.12.4.401

Utomo, S.D., 2005. Pengaruh L-Sistein terhadap efisiensi transformasi genetik jagung (Zea mays) menggunakan Agrobacterium. Bul. Agron., 33: 7-16. 